\title{
Awareness of Risk Factors for Non Communicable Diseases among Adolescent girls aged 15-17 years in Koti, Hyderabad
}

\author{
Authors \\ Rajarikam Shravani ${ }^{1}$, R.L. Lakshman Rao ${ }^{2}$, Md. Abdul Wassey ${ }^{3}$, Nazia Tabassum ${ }^{4}$ \\ ${ }^{1,3}$ Post graduate, ${ }^{2}$ Professor and Head of the Department, ${ }^{4}$ Senior Resident. \\ Department of Community Medicine, Osmania Medical College, Hyderabad \\ Corresponding Author \\ Nazia Tabassum
}

Senior Resident, Department of Community Medicine, Osmania Medical College, Hyderabad

\begin{abstract}
Background: In India Non Communicable Diseases (NCDs) are estimated to account for about $53 \%$ of all deaths. The importance of adolescent age group lies in the fact that many serious diseases in adulthood have their roots in adolescence.

Objectives: To assess the awareness of risk factors for Non Communicable Diseases among junior college adolescent girls aged 15-17 years

Methodology: A cross sectional study was done among 240 adolescent girls of a private junior college in Hyderabad by using convenient sampling method. A self administered predesigned questionnaire was used for data collection.

Results and Discussion: Majority of the students (72\%) belong to upper lower socio economic class. Most of the adolescent girls were aware that junk food and sedentary life style are risk factors for obesity and high salt intake as a risk factor for Hypertension. The awareness of Obesity as a risk factor for Diabetes Mellitus was found only in $38 \%$ of the students.

Keywords: Adolescent girls, non communicable disease, obesity.
\end{abstract}

\section{Introduction}

Non Communicable Diseases (NCDs) are the leading cause of death globally. India is in the stage of epidemiological transition where the disease burden is shifting from communicable diseases to non communicable disease ${ }^{1}$. The sustainable development goals (SDGs) target 3.4 calls for a one third reduction in premature mortality from NCDs by $2030^{2}$. The behavioural risk factors responsible for NCDs are tobacco use, unhealthy diet, physical inactivity, harmful use of alcohol $^{3}$. The World Health Organization has already warned of increasing NCDs among adolescent as a major public health problem.

As per Census India 2011, in India almost 60 percent of premature deaths among adults can be associated with behavior or conditions that began or occurred during adolescence (WHO 2002). Nearly 2 per 1,000 adolescent girls and 1 per 1,000 adolescent boys aged 15-19 suffer from diabetes ${ }^{4}$. Not only NCDs affect the health of girls and women, but also they affect the health and life 
style of their children. Female Adolescent Health is the key to sustainable development and hence changing the lifestyle of a girl for the better, unlocks their potential to change and thus improves the whole society ${ }^{5}$.

\section{Materials and Methods}

Institutional based cross sectional study was done in Jan-march 2016, in a Private Junior college (English medium), Koti with 240 female students. Convenient sampling was done to select the place of the study. The students who were enrolled in the college belonged to different branches like Biology, Mathematics and Economics branches of Intermediate education. The total intake of college is 240 students who belonged to various above mentioned branches. A total of 208 students were present in the college on the day of study and all of them were taken into the study after taking the informed consent from the concerned principal of the college ensuring that confidentiality will be maintained.

A pre designed semi structured questionnaire was used as a study tool. The proforma was explained to the students in detail prior to the distribution for collection of data. Data was entered in Microsoft Excel 2007 and univariate analysis was done.

\section{Results}

In the present study all the participants were female students belonging to 15-17 years age group. The data was collected by using a self administered proforma. Out of 208 proformas which were received only 200 were complete and thus analysis was done only for 200 students. Out of the 200 students awareness for smoking as risk factor for cardiovascular diseases was found in $75 \%$ (150), awareness for diabetes as a risk factor for cardiovascular diseases was found in only $45 \%$ (90), awareness for hypertension as a risk factor for cardiovascular diseases was found in $75 \%(150)$ and for Obesity was found in $70 \%(140)$.

Table no: 1 Socio economic classification of study population

\begin{tabular}{l|c|c|}
\hline KUPPUSWAMY CLASSIFICATION & Number & Percentage \\
\hline UPPER(I) & 0 & $0 \%$ \\
\hline UPPER MIDDLE(II) & 6 & $3.00 \%$ \\
\hline MIDDLE/LOWER MIDDLE(III) & 36 & $18.00 \%$ \\
\hline LOWER/UPPER LOWER (IV) & 144 & $72.00 \%$ \\
\hline LOWER(V) & 14 & $7.00 \%$ \\
\hline TOTAL & 200 & $100 \%$ \\
\hline $72 \%$ students were from the upper lower \\
socioeconomic class.
\end{tabular}

Figure no: 1 Awareness of risk factors of obesity among study population

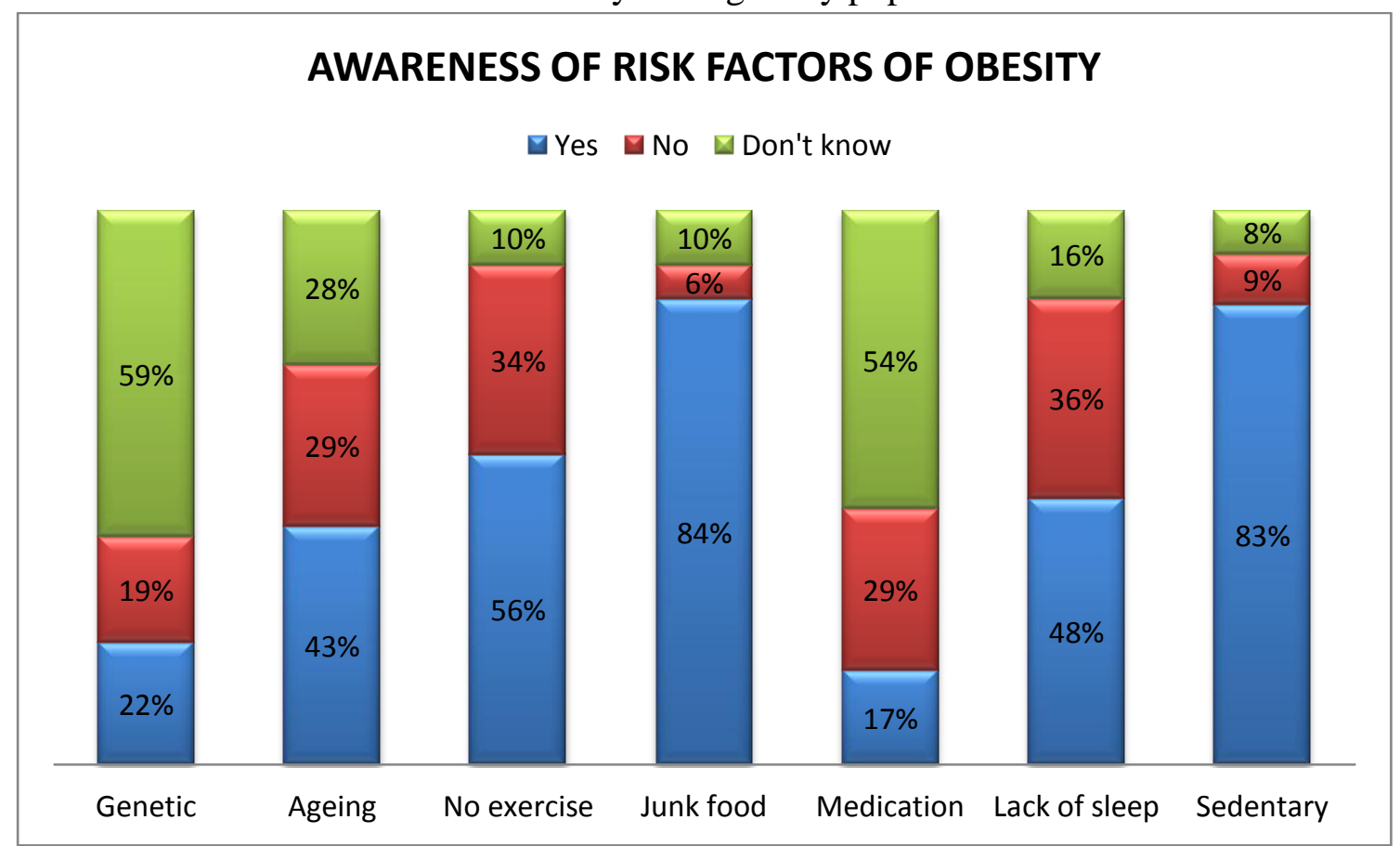


Majority of the students were aware that junk food and sedentary life style are the major risk factors for obesity. $48 \%$ students were aware that lack of sleep is a risk factor for obesity. Around 54\% (108) of the girls responded as they don't know that any medication could also lead to Obesity.

Figure no: 2 Awareness of risk factors of hypertension among study population

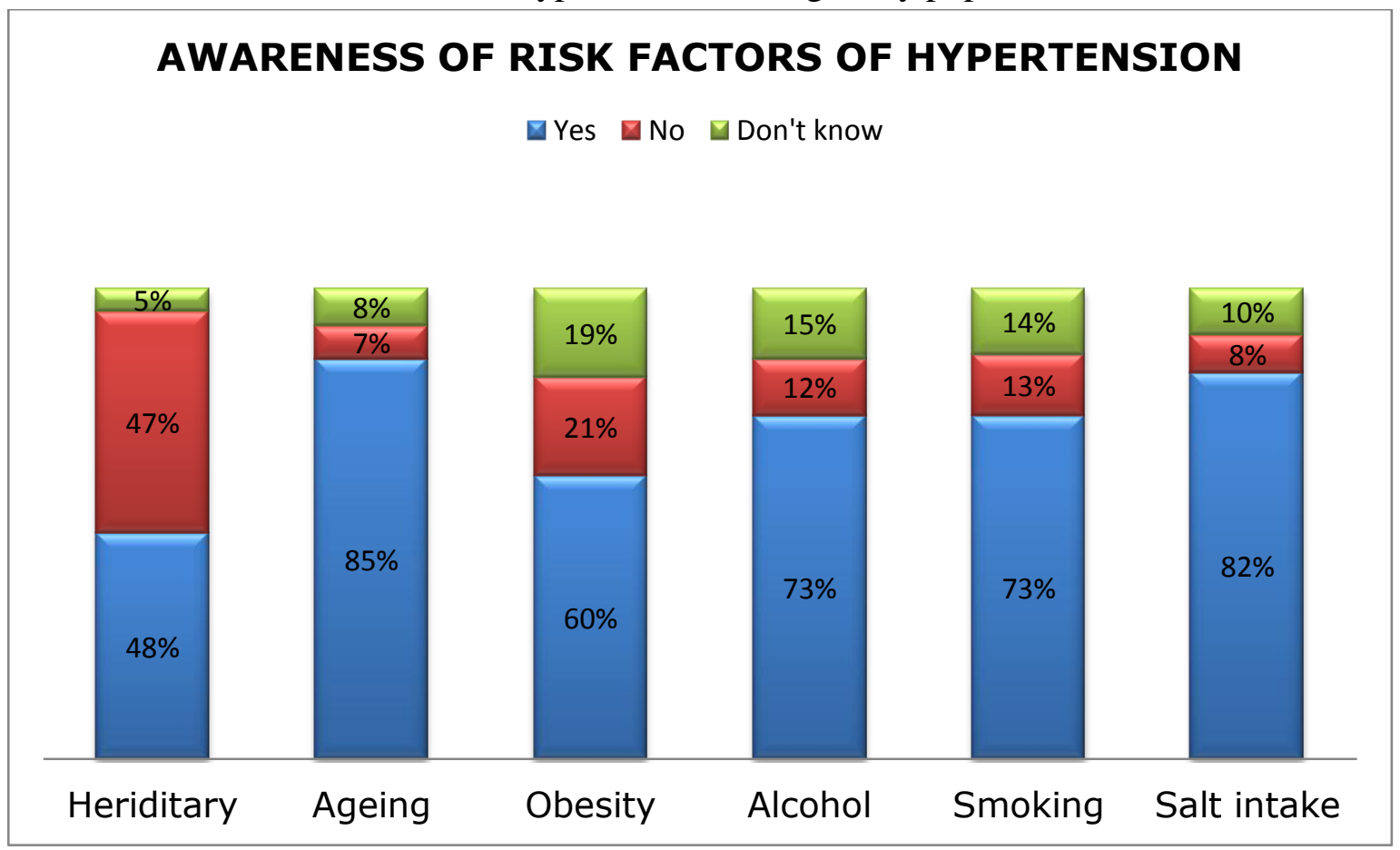

Awareness of ageing, smoking and high salt intake as risk factors for hypertension was found in $85 \%, 73 \%$ and $82 \%$ of the students respectively.

Figure no: 3 Awareness of risk factors of diabetes mellitus among study population

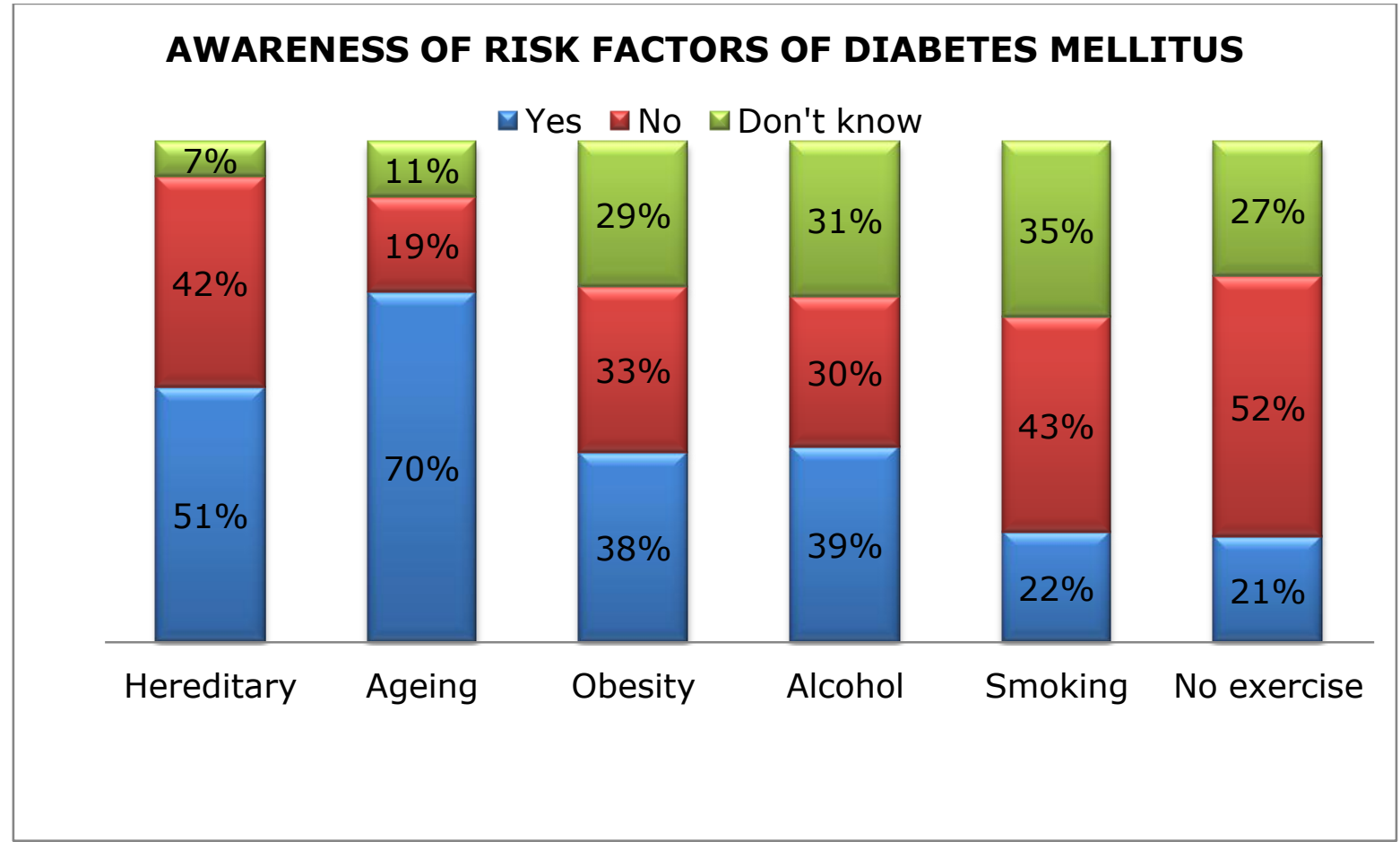

The awareness of Ageing and Obesity as the risk factors for Diabetes Mellitus was found in $70 \%$ and $38 \%$ of the students respectively. 
Table No: 2 Awareness of risk factors of non communicable diseases among study population

\begin{tabular}{|c|c|c|c|c|c|c|c|}
\hline \multirow[t]{2}{*}{ RISK FACTOR } & \multicolumn{2}{|c|}{ YES } & \multicolumn{2}{|c|}{ NO } & \multicolumn{2}{|c|}{$\begin{array}{l}\text { DON'T } \\
\text { KNOW } \\
\end{array}$} & \multirow[t]{2}{*}{ TOTAL } \\
\hline & No. & $\%$ & No. & $\%$ & No. & $\%$ & \\
\hline \multicolumn{8}{|l|}{$\begin{array}{l}\text { AWARENESS OF RISK FACTORS OF OBESITY/ } \\
\text { OVERWEIGHT AMONG STUDY SUBJECTS }\end{array}$} \\
\hline GENETIC DISEASE/FAMILIAL DISEASE & 44 & $22.00 \%$ & 38 & $19.00 \%$ & 118 & $59.00 \%$ & 200 \\
\hline AGING & 86 & $43.00 \%$ & 58 & $29.00 \%$ & 56 & $28.00 \%$ & \\
\hline LACK OF EXERCISE & 112 & $56.00 \%$ & 68 & $34.00 \%$ & 20 & $10.00 \%$ & 200 \\
\hline JUNK FOOD & 168 & $84.00 \%$ & 12 & $6.00 \%$ & 20 & $10.00 \%$ & 200 \\
\hline MEDICATION & 34 & $17.00 \%$ & 58 & $29.00 \%$ & 108 & $54.00 \%$ & 200 \\
\hline LACK OF SLEEP & 96 & $48.00 \%$ & 72 & $36.00 \%$ & 32 & $16.00 \%$ & 200 \\
\hline SEDENTARY NATURE OF WORK & 166 & $83.00 \%$ & 18 & $9.00 \%$ & 16 & $8.00 \%$ & 200 \\
\hline \multicolumn{8}{|l|}{$\begin{array}{l}\text { AWARENESS OF } \\
\text { HYPERTENSION }\end{array}$} \\
\hline HERIDITARY & 96 & $48.00 \%$ & 96 & $47.00 \%$ & 10 & $5.00 \%$ & 200 \\
\hline AGE ADVANCEMENT & 170 & $85.00 \%$ & 14 & $7.00 \%$ & 16 & $8.00 \%$ & 200 \\
\hline OBESITY & 120 & $60.00 \%$ & 42 & $21.00 \%$ & 38 & $19.00 \%$ & 200 \\
\hline ALCOHOL & 146 & $73.00 \%$ & 42 & $12.00 \%$ & 30 & $15.00 \%$ & 200 \\
\hline SMOKING & 146 & $73.00 \%$ & 26 & $13.00 \%$ & 28 & $14.00 \%$ & 200 \\
\hline INCREASE INTAKE OF SALT & 164 & $82.00 \%$ & 16 & $8.00 \%$ & 20 & $10.00 \%$ & 200 \\
\hline \multicolumn{8}{|l|}{$\begin{array}{l}\text { AWARENESS OF RISK FACTORS OF DIABETES } \\
\text { MELLTUS }\end{array}$} \\
\hline HEREDITARY & 102 & $51.00 \%$ & 84 & $42.00 \%$ & 14 & $7.00 \%$ & 200 \\
\hline AGE ADVANCEMENT & 140 & $70.00 \%$ & 38 & $19.00 \%$ & 22 & $11.00 \%$ & 200 \\
\hline OBESITY & 76 & $38.00 \%$ & 66 & $33.00 \%$ & 58 & $29.00 \%$ & 200 \\
\hline ALCOHOL INTAKE & 78 & $39.00 \%$ & 60 & $30.00 \%$ & 62 & $31.00 \%$ & 200 \\
\hline SMOKING & 44 & $22.00 \%$ & 86 & $43.00 \%$ & 70 & $35.00 \%$ & 200 \\
\hline LACK OF EXERCISE & 42 & $21.00 \%$ & 104 & $52.00 \%$ & 54 & $27.00 \%$ & 200 \\
\hline
\end{tabular}

\section{Discussion}

The aim of the study was to study the awareness of certain risk factors of non communicable disease like obesity, hypertension and diabetes among adolescent girls. The risk factors assessed were age, lack of exercise, genetic, junk food consumption, drugs, lack of sleep, obesity ,smoking, high salt intake, Alcohol, sedentary life style and lack of physical exercise for obesity, hypertension and diabetes.

Majority of the adolescent students were aware that junk food and sedentary life style are the major risk factors for obesity and 48\%(96) were aware that lack of sleep is a risk factor for obesity. In study conducted by Shivalli $\mathrm{S}$. et al it was found that $18.2 \%$ were aware that increase in body mass index is an indicator of obesity ${ }^{6}$.
In this study the awareness of ageing and salt intake as risk factors for hypertension was found in $85 \%(170)$ and 82\%(164) students respectively whereas the awareness of smoking and obesity as hypertension risk factors was found in only $73 \%$ (146) and 60\%(120) students respectively. In a study conducted by Shivalli $\mathrm{S}$. et al it was found that $54.1 \%$ and $47.4 \%$ adolescents were aware that tobacco use and obesity were risk factors for hypertension ${ }^{6}$.

In the study done by Chaudhari et al found that the baseline knowledge of the students regarding the risk factors of hypertension such as high salt consumption, obesity, stress, and lack of physical activity was $25.9 \%, 23.3 \%, 65.5 \%$, and $21.6 \%$, respectively, which was significantly increased to $73.3 \%, 61.2 \%, 92.2 \%$, and $45.7 \%$, respectively, after the intervention ${ }^{7}$. 
In this study the awareness of obesity, ageing and family history of diabetes mellitus as risk factors for Diabetes mellitus was found in 38\%(76), $70 \%(140)$ and $51 \%(102)$ of the students respectively whereas in the study by Shivalli S. et ${ }^{6}$ al the awareness for same risk factors was found in only $47.4 \%, 27 \%$ and $27.1 \%$ of the adolescents. The overall awareness of risk factors for non communicable disease was not satisfactory .Similar results found in study conducted by Divakaran B et $\mathrm{al}^{8}, 84.8 \%$ adolescents were having very low awareness about the risk factors for non communicable diseases. In study conducted by Anju ade et $\mathrm{al}^{9}$ only half the adolescents were aware of diabetes risk factors.

\section{Conclusion}

Primordial prevention is the key intervention for preventing Non communicable diseases so there is a need and scope for the health education activity regarding risk factors of non communicable disease to promote healthy life style among students. There is a need for focus on adolescent girls in NPCDCS Programme to prevent and control common NCDs by encouraging behavior and life style changes. More importantly, adolescence provides an opportune time for positive behaviour modification, to mitigate the emergence of risk factors of Non Communicable Diseases (NCDs). Because the main preventable risk factors for NCDs such as poor dietary habits and sedentary lifestyles have their beginnings in this age.

\section{References}

1. Ministry of Health and Family Welfare Government of India. National Health Policy 2017; 2017. Available from https://mohfw.gov.in/sites/default/files/914 7562941489753121.pdf [Accessed on 1003-2018]

2. United Nations. Sustainable Development Goals; 2015. Available from https://sustainabledevelopment.un.org/sdg

3 [ Accessed on 12-03-2018]

3. Park.k. Park's textbook of preventive and social medicine. $24^{\text {th }}$ ed. Jabalpur: Banarsidas Bhanot; 2017. P381.

4. World Health Organization. 'Factsheet on adolescent health, India'. 2011.

5. World Health Organization. "NonCommunicable Diseases: A priority for Women's Health and Development". WHO: 2011. Available from http://www.who.int/pmnch/topics/maternal 12011_women_ncd_report.pdf.pdf Accessed on 15-03-2018]

6. Shivalli S, Gupta MK, Mohaptra A, Srivastava RK. Awareness of non communicable diseases and their risk factors among rural school children. Indian Journal of Community Health. 2013 Jan 31;24(4):332-5.

7. Chaudhari AI, Rami K, Thakor N. Assessment of knowledge regarding noncommunicable diseases and their risk factors among students of higher secondary school: an interventional study. Int J Med Sci Public Health 2016;5:115118.

8. Divakaran B, Muttapillymyalil J, Sreedharan J, Shalini K. Lifestyle risk factors of non communicable diseases: awareness among school children. Indian journal of cancer. $2010 \mathrm{Jul} \mathrm{1;47(5):9.}$

9. Ade A, Chethana KV, Mane A, Hiremath SG. Non-communicable diseases: awareness of risk factors and lifestyle among rural adolescents. Int $\mathrm{J}$ Biol Med Res. 2014;5(1):3769-71. 